\title{
Occupational Violence and Staff Safety in Health-Care: A Cross-Sectional Study in a Large Public Hospital
}

\author{
Zainab R Al-Shaban' \\ Sultan T Al-Otaibi ${ }^{2}$ \\ Hatem A Alqahtani $\mathbb{D}^{3}$ \\ 'Primary Healthcare Centers, \\ Department of Occupational Medicine, \\ Ministry of Health, Qatif, Kingdom of \\ Saudi Arabia; ${ }^{2}$ Department of Public \\ Health, College of Public Health, Imam \\ Abdulrahman Bin Faisal University, \\ Dammam, Kingdom of Saudi Arabia; \\ ${ }^{3}$ Department of Family and Community \\ Medicine, College of Medicine, Imam \\ Abdulrahman Bin Faisal University, \\ Dammam, Kingdom of Saudi Arabia
}

Background: Physical and psychological workplace violence in health-care settings has serious implications for the health of workers, as well as a negative effect on productivity and health-care quality.

Methods: A cross-sectional study was conducted from May to July 2018 among physicians and nurses using a convenience sample $(n=213)$ for the previous 12 months at a tertiary hospital in Dammam, Saudi Arabia. The participants completed a self-administered questionnaire that assessed their personal and professional characteristics, whether they had experienced physical violence (assault) or psychological violence as health-care practitioners, and whether they had reported the incidents.

Results: Among the respondents, 57\% had experienced psychological violence, $6 \%$ had experienced physical violence, and $37 \%$ had experienced both psychological and physical violence in the previous 12 months. Shiftwork and working in the inpatient department were associated with a significant increase in the risk of physical violence. However, these factors showed no difference with regard to psychological violence. Both physical and psychological violence had diverse causes, without any single predominant cause. Similarly, both forms of violence occurred in multiple departments. Many of the incidents were unreported $(75 \%$ of incidents involving psychological violence and $39 \%$ involving physical violence).

Conclusion: Physical and psychological violence against health-care workers (HCWs) in the hospital under study was found to be very common. The results of this study suggest the need to develop and evaluate a violence prevention program to achieve quality health-care services.

Keywords: occupational, health-care, violence, large hospital

\section{Introduction}

Workplace violence, particularly among health-care workers (HCWs), is a global problem and has become a major concern in many countries. ${ }^{1}$ It is characterized by episodes where workers are physically assaulted, undermined, or ambushed in situations associated with their work-including driving to and from work, which poses an explicit or implicit challenge to their safety, well-being, prosperity, or health. ${ }^{2}$

According to the World Health Organization (WHO), workplace violence can be physical or psychological. Physical violence is defined as 
the use of physical force against another person or group that results in physical, sexual or psychological harm. It includes beating, kicking, slapping, stabbing, shooting, pushing, biting and pinching. (adapted from the WHO definition of violence) ${ }^{1}$

Psychological violence, in contrast, is defined as

intentional use of power, including threat of physical force, against another person or group that can result in harm to physical, mental, spiritual, moral or social development. It includes verbal abuse, bullying/mobbing, harassment and threats. (adapted from the WHO definition of violence) ${ }^{1}$

HCWs carry the highest risk of workplace violence were the reported rates differ by country. ${ }^{3} \mathrm{~A}$ recent review suggested that violence against HCWs accounts for $75 \%$ of all cases of workplace violence. ${ }^{4,5}$ Some studies have also indicated that up to $90 \%$ of HCWs have experienced violent incidents at work. ${ }^{6,7}$ Among HCWs, nurses and physicians are particularly likely to experience violence because the nature of their work requires frequent interactions with patients and patients' relatives. ${ }^{8-11}$

An analysis of violence against HCWs could lead to the prioritization of prevention strategies to minimize the negative impact of violence on HCWs' psychological and physical well-being and mitigate job dissatisfaction, high turnover, and financial loss for employees and employers. Unlike private hospitals, government hospitals in Saudi Arabia provide free health services. As a result, the hospitals do not only have large health-care staff sizes but also receive numerous patients and visitors. These factors increase the risk of experiencing violence from patients, patients' relatives, and even colleagues. Only a few studies have been conducted on HCWs' experience of violence in the workplace in Saudi Arabia, especially in the Eastern Province. $^{8,11}$ The studies that have been conducted in Saudi Arabia focused only on the prevalence of physical workplace violence among nurses. Hence, this study was conducted in a large government hospital in Dammam, Saudi Arabia, to evaluate both physical and psychological violence against nurses and physicians and their personal and professional characteristics. The study also aimed to identify the factors associated with such violence and to collect data on the documentation of incident reporting and the subsequent handling of reported incidents.

\section{Methods}

A cross-sectional study was conducted from May to July 2018 among HCWs (physicians and nurses) at a 500- bed government hospital: Dammam Medical Complex in Dammam, Eastern Province, Saudi Arabia. This hospital offers inpatient, outpatient, and emergency room services.

The study protocol was approved by the Hospital Research Approval Committee. The authors were not affiliated with this governmental hospital, which was selected in order to obtain a large sample size. Being unacquainted with the working staff in this hospital, we excluded bias and added to the findings of our study. Furthermore, the hospital endorsed our study, and a verbal consent was approved by the ethical committee; subsequently, verbal consent was obtained from each participant as no invasive procedures were involved in our study. All personal data were kept confidential and used only for the purposes of the study. Participation was voluntary. All procedures involving human participants were conducted in accordance with the ethical standards of the institutional and/or national research committee and with the 1964 Helsinki Declaration and its later amendments, or with comparable ethical standards.

The study sample consisted of physicians (general, specialist, and consultant) and nurses. Interns (physicians or nurses usually in one year training who have completed medical school or nursing school and have a degree but do not yet have their license to practice medicine) and rotators (students during their final year of study) who work at other hospitals were excluded from the study. There is a possibility that interns and rotators were less confident when dealing with challenging patients and, therefore, at a greater risk of violence; however, we excluded them from this study because their numbers were small, and they had a high turnover (with some of them working at the Dammam Medical Complex for a maximum of 1 month). A structured, validated, self-administered questionnaire was used from those of the International Labor Office, the International Council of Nurses, the WHO, and Public Services International. ${ }^{12}$ The questionnaire contained 7 sections. The first 4 sections contained questions about sociodemographic characteristics such as age, sex, job title, level of education, marital status, nationality, and years of experience. The fifth section contained questions about incidents of physical violence experienced in the last 12 months and the causes and characteristics of the attacks. The sixth section assessed incidents of psychological violence experienced in the last 12 months. The final section focused on incident reporting, including causes of incidents not being report and satisfaction with the action taken. The questionnaire was conducted in English. In the 
pilot study, the questionnaire was administered to 10 physicians and 10 nurses from the hospital to test the clarity of the questions. Then the questionnaire was distributed to a convenience sample of $260 \mathrm{HCWs}$ (ie, workers who were present at the time of the study were invited to participate, rather than using the method that involves selecting workers in advance from personnel files). Out of the $260 \mathrm{HCWs}, 213$ returned the completed questionnaire (an $82 \%$ participation rate). Among the 213 respondents, $147(69 \%)$ reported that they had experienced workplace violence; thus, the remaining 66 respondents (31\%) were excluded from the final statistical analysis.

The data obtained were entered into Microsoft Excel and imported into the statistical package for the social sciences (SPSS), software version 20.0. All the statistical analyses were performed with SPSS. Spot checks for the quality of data entered were done. Frequency counts and cross-tabulations were run to identify completeness, abnormal/illogical values, and inconsistencies. The statistical tests used included the student $t$-test, the chi-square test, and regression analysis. P-value of less than 0.05 was taken as the level of statistical significance. Multivariable logistic analysis with prespecified predictor variables was conducted for physical violence, psychological violence, and both combined to calculate the odds ratio (OR) and 95\% confidence interval (CI) for the association between the physical and psychological workplace violence that was experienced and risk factors. The prediction variables were selected from those found to be significant in the initial statistical analysis (p-value less than 0.05), and the sociodemographic variables sex and job were included. Highly correlated variables were not included in the same model.

\section{Results}

In the present study, out of 213 respondents, 147 had encountered either physical or psychological workplace violence. Of the 147 respondents exposed to workplace violence, 91 (62\%) were women. Most of the respondents (122 or $83 \%$ ) were aged $20-35$ years, and $103(70 \%)$ were married. Most of the respondents (113 or $77 \%$ ) were Saudis, while 34 (23\%) were non-Saudis. Of the 147 respondents who experienced workplace violence, 75 (51\%) were nurses, while 72 (49\%) were physicians. The nurses who participated in the study were predominately female 47 (62\%), while two-thirds of the physicians were male. A majority of the respondents (78 or 53\%) were working from 8:00 AM to 4:00 PM, 5 days a week, rather than in shifts. Of all the respondents, $100(68 \%)$ worked in the inpatient departments, and 47 (32\%) worked in the outpatient department. Most of the respondents (97 or $66 \%$ ) had 1 to 5 years of work experience in the health sector.

Among the respondents, $84(57 \%)$ reported a history of having experienced psychological violence only, 9 (6\%) reported a history of physical violence only, while 54 (37\%) reported having experienced both types of violence in the previous 12 months. Verbal abuse was the most frequent form of psychological violence (58 or 69\%), followed by threats (19 or 23\%) and bullying/mobbing ( 7 or $8 \%$ ). Pushing and beating were the most common forms of physical violence: 4 or $47 \%$ and 3 or $28 \%$, respectively.

Personal and work factors associated with violence are summarized in Table 1. Younger respondents (35 years or younger) experienced increased physical and psychological forms of violence $(p=0.005$ and $p<0.001$, respectively), as did respondents with a shorter work history $(<5$ years, $p=0.028$ and $p=0.005$, respectively). Although not statistically significant, in comparison to males, higher proportions of females reported both types of violence. Married individuals were more frequently subjected to violence compared to those who were not married. Violence was not limited to 1 age group, as the proportion of workers who experienced violence in the youngest age range ( $<35$ years) and the middle range (36-50 years) was similar.

Regarding work factors, the physicians and the nurses did not differ statistically in the likelihood of experiencing either type of violence. Shiftwork and working in the inpatient department were associated with a significant increase in the risk of physical violence $(\mathrm{p}=0.001)$. However, these factors were not significantly associated with psychological violence. Physicians or nurses who worked in shifts in the inpatient department experienced the highest rate of physical violence compared to other workers $(\mathrm{p}=0.006)$.

When asked about the primary perpetrators of physical violence, respondents reported that half the incidents were initiated by patients, followed by the patients' relatives (46 or $45 \%$ ). For psychological violence, patients and their relatives were equally frequent as perpetrators. Both physical and psychological violence had diverse causes but no predominant cause.

Respondents were also asked about the reporting of incidents. Among the 36 respondents who experienced physical violence, 14 (39\%) did not report the incident. 
Table I Personnel and Work Factors Associated with Violence

\begin{tabular}{|c|c|c|c|c|c|c|}
\hline & \multicolumn{3}{|c|}{ Physical } & \multicolumn{3}{|c|}{ Psychological } \\
\hline & $\mathbf{n}$ & $\%$ & $p$-value & $\mathbf{n}$ & $\%$ & $p$-value \\
\hline \multicolumn{7}{|l|}{ Sex } \\
\hline Male & 19 & 53 & 0.191 & 37 & 33 & 0.063 \\
\hline Female & 17 & 47 & & 74 & 67 & - \\
\hline \multicolumn{7}{|l|}{ Age (years) } \\
\hline 20-35 & 22 & 62 & $0.005^{*}$ & 101 & 91 & $\mathrm{p}<0.00 \mathrm{I}^{*}$ \\
\hline $36-50$ & 7 & 19 & & II & 9 & - \\
\hline$>50$ & 7 & 9 & & 0 & 0 & - \\
\hline \multicolumn{7}{|l|}{ Marital status } \\
\hline Single & 11 & 31 & 0.698 & 26 & 20 & 0.061 \\
\hline Married & 23 & 64 & & 80 & 72 & - \\
\hline Other & 2 & 6 & & 5 & 8 & - \\
\hline \multicolumn{7}{|l|}{ Nationality } \\
\hline Saudi & 25 & 69 & 0.056 & 88 & 79 & 0.345 \\
\hline Non-Saudi & 11 & 31 & & 23 & 21 & - \\
\hline \multicolumn{7}{|l|}{ Experience } \\
\hline$<$ l year & 1 & 3 & $0.028 *$ & 11 & 10 & $0.005^{*}$ \\
\hline $\mathrm{I}-5$ years & 25 & 69 & & 72 & 65 & - \\
\hline$>5$ years & 10 & 28 & & 28 & 25 & - \\
\hline \multicolumn{7}{|l|}{ Job Title } \\
\hline Physician & 20 & 56 & 0.073 & 52 & 47 & 0.367 \\
\hline Nurse & 16 & 44 & & 59 & 53 & - \\
\hline \multicolumn{7}{|l|}{ Shift Work } \\
\hline Yes & 13 & 43 & $\mathrm{P}<0.00 \mathrm{I} *$ & 56 & 50 & 0.345 \\
\hline No & 23 & 64 & & 55 & 50 & - \\
\hline \multicolumn{7}{|l|}{ Department } \\
\hline Outpatient & 7 & 19 & $0.006 *$ & 40 & 36 & 0.089 \\
\hline Inpatient & 29 & 81 & & 71 & 64 & - \\
\hline
\end{tabular}

Notes: $n=$ number; $\%=$ percentages among that reporting violence; ${ }^{*} p<0.05$ (Chi square or Fisher's exact test if the observations less than 5 )

Also, three-quarters of incidents associated with psychological violence (81 of 111 incidents) were unreported. The majority of the respondents (50 or 34\%) felt that reporting the violent episode was useless or not important.
About $6(6 \%)$ of those who experienced psychological violence feared possible negative consequences of reporting. Among the respondents who reported dissatisfaction with the handling of an incident, 69 (47\%) were female, 63 (43\%) were physicians, while 95 (65\%) were Saudis. The differences were statistically significant: $p=0.01$ (Table 2).

Multivariable logistic analysis with prespecified predictor variables was conducted for physical violence, psychological violence, and both combined (Table 3-5). The prediction variables included department, experience, nationality, sex, and job. The workers' age was not included due to its strong association with their experience. The results of these models showed that for physical violence, nationality (comparing Saudi to non-Saudi) was a significant factor (OR = $3.85, \mathrm{p}=0.023, \mathrm{CI}=1.2-12.3)$. Saudis had nearly 4 times higher odds of experiencing physical violence than non-Saudis. The risk of psychological violence was lower among workers with more than 5 years of work experience $(\mathrm{OR}=0.51, \mathrm{p}=0.074, \mathrm{CI}=0.25-1.1)$ and those with less than 1 year $(\mathrm{OR}=0.21, \mathrm{p}=0.019$, $\mathrm{CI}=0.06-0.77)$, compared to workers with 1 to 5 years of work experience.

For the experience of physical violence, psychological violence, or both combined, the respondent's department, the respondent's department and experience were highly significant factors. The department of the respondent (comparing outpatient to inpatient) had an OR of $3.26, p=0.008$, and CI $=1.35-7.84$. This shows that the odds of experiencing any type of violence were 3 times higher among workers in the inpatient department than the outpatient department. Work experience had similar results with the psychological violence model, with an OR of $0.55 \mathrm{p}=0.139$, and $\mathrm{CI}=0.26-1.2$ and an OR of $0.17, \mathrm{p}=0.009$, and $\mathrm{CI}=0.05-0.64$ for workers with more than 5 years and less than 1 year of work experience, respectively. The odds of experiencing any type of

Table 2 Relationship of Satisfactions Level with Incident Handling and Respondents' Characteristics

\begin{tabular}{|l|l|c|c|c|c|c|c|}
\hline \multicolumn{2}{|l|}{ Characteristics } & Satisfied & $\%$ & Dissatisfied & $\%$ & $\chi^{2}$ & $\boldsymbol{p}$-value \\
\hline Gender & Male & 18 & 12 & 48 & 33 & 6.044 & $0.014 *$ \\
& Female & 12 & 8 & 69 & 47 & 5.430 \\
\hline \multirow{2}{*}{ Job } & Physician & 9 & 6 & 63 & 43 & 0.020 \\
& Nurse & 21 & 14 & 54 & 65 & 4.450 & 0.030 \\
\hline \multirow{2}{*}{ Nationality } & Saudi & 18 & 12 & 95 & 16 & & \\
& Non-Saudi & 11 & 7 & 23 & & \\
\hline
\end{tabular}

Notes: \% = percentage; ${ }^{*} p$ value calculated from Fisher's exact test or Chi square $\left(\chi^{2}\right)$ test. 
Table 3 Multivariable Logistic Analysis with Pre-Specified Model for Psychological Violence

\begin{tabular}{|c|c|c|c|c|c|c|}
\hline Psychological Violence & OR & S.E & $\mathbf{z}$ & $p>z$ & \multicolumn{2}{|c|}{$[95 \% \mathrm{CI}]$} \\
\hline Job (Physician to Nurse) & 1.13 & 0.44 & 0.31 & 0.756 & 0.52 & 2.44 \\
\hline Sex (male to female) & 0.59 & 0.23 & -1.33 & 0.184 & 0.27 & 1.28 \\
\hline Department (outpatient to inpatient) & 1.80 & 0.69 & 1.51 & 0.13 & 0.84 & 3.82 \\
\hline Nationality (Saudi to non-Saudi) & 1.69 & 0.70 & 1.3 & 0.194 & 0.76 & 3.71 \\
\hline \multicolumn{7}{|l|}{ Experience } \\
\hline Experience (more than 5 yrs. to ref) & 0.52 & 0.19 & -1.79 & 0.074 & 0.25 & 1.06 \\
\hline Experience (less than I yrs. to ref) & 0.21 & 0.14 & -2.36 & 0.019 & 0.06 & 0.77 \\
\hline Constant & 0.77 & 0.87 & -0.23 & 0.818 & 0.08 & 6.97 \\
\hline
\end{tabular}

Abbreviations: $\mathrm{OR}$, odds ratio; $\mathrm{SE}$, standard error; $\mathrm{z}, \mathrm{z}$-value; $\mathrm{Cl}$, confidence interval.

Table 4 Multivariable Logistic Analysis with Pre-Specified Model for Physical Violence

\begin{tabular}{|c|c|c|c|c|c|c|}
\hline Physical Violence & OR & SE & $\mathbf{z}$ & $p>z$ & \multicolumn{2}{|c|}{$[95 \% \mathrm{CI}]$} \\
\hline Job (Physician to Nurse) & 0.49 & 0.22 & -1.55 & 0.120 & 0.20 & 1.20 \\
\hline Sex (male to female) & 0.96 & 0.46 & -0.08 & 0.937 & 0.38 & 2.45 \\
\hline Department (outpatient to inpatient) & 1.66 & 0.69 & 1.21 & 0.228 & 0.73 & 3.77 \\
\hline Nationality (Saudi to non-Saudi) & 3.85 & 2.28 & 2.28 & 0.023 & 1.21 & 12.29 \\
\hline \multicolumn{7}{|l|}{ Experience } \\
\hline Experience (more than 5 years to ref) & 1.06 & 0.47 & 0.14 & 0.891 & 0.45 & 2.52 \\
\hline Experience (less than I year to ref) & 0.32 & 0.36 & -1.03 & 0.305 & 0.04 & 2.78 \\
\hline Constant & 0.03 & 0.05 & -2.29 & 0.022 & 0.002 & 0.61 \\
\hline
\end{tabular}

Abbreviations: OR, odds ratio; SE, standard error; z, z-value; $\mathrm{Cl}$, confidence interval.

Table 5 Multivariable Logistic Analysis with Pre-Specified Model for Combined Violence

\begin{tabular}{|c|c|c|c|c|c|c|}
\hline Combined Violence & OR & SE & $\mathbf{z}$ & $p>z$ & \multicolumn{2}{|c|}{$[95 \% \mathrm{Cl}]$} \\
\hline Job (Physician to Nurse) & 1.02 & 0.43 & 0.05 & 0.958 & 0.45 & 2.33 \\
\hline Sex (male to female) & 0.57 & 0.24 & -1.33 & 0.183 & 0.25 & 1.30 \\
\hline Department (outpatient to inpatient) & 3.26 & 1.46 & 2.64 & 0.008 & 1.36 & 7.84 \\
\hline Nationality (Saudi to non-Saudi) & 2.07 & 0.90 & 1.67 & 0.094 & 0.88 & 4.84 \\
\hline \multicolumn{7}{|l|}{ Experience } \\
\hline Experience (more than 5 years to ref) & 0.56 & 0.22 & -1.48 & 0.139 & 0.26 & 1.21 \\
\hline Experience (less than I year to ref) & 0.17 & 0.11 & -2.62 & 0.009 & 0.05 & 0.64 \\
\hline Constant & 0.40 & 0.49 & -0.75 & 0.452 & 0.04 & 4.33 \\
\hline
\end{tabular}

Abbreviations: OR, odds ratio; SE, standard error; z, z-value; $\mathrm{Cl}$, confidence interval.

violence were much greater for workers with 1 to 5 years of work experience than any other group.

\section{Discussion}

The data in this study revealed that the experience of workplace violence is high, as $69 \%$ of the participants had faced violence in the preceding 12 months. Also, psychological violence was found to be more frequent than physical violence. Verbal abuse was found to be the most frequent form of psychological violence in this study, while pushing was the highest form of physical violence. The risk of being subjected to violence was the same among the age groups of the participants. However, because the workers were predominantly young, younger HCWs accounted for the largest number of incidents of both physical and psychological violence. Males and 
females had comparable risks of workplace violence. We also found a statistically nonsignificant trend for a greater experience of violence among nurses in comparison to physicians.

Violence rates were significantly different among the departments in the hospital. The inpatient department had higher rates of violence than other departments. Patients were responsible for half of the incidents of physical violence, while relatives were less frequently identified as perpetrators. The reverse was found for psychological violence, as relatives were more frequently the cause of the violence.

The respondents had different opinions about the cause of physical and psychological violence. Conditions such as unmet patient demands, patient health conditions, and overcrowding as perceived by patients were frequently reported as the causes of physical violence. However, factors related to supervisors and coworkers were most frequently reported as the causes of psychological violence.

Identification and reporting of episodes of violence are essential to assist the victims. Complete reporting is also necessary to design and evaluate prevention programs. The benefits of the programs should be carefully evaluated and compared to alternative approaches for cost-effectiveness. Despite the importance of reporting, almost $73 \%$ of psychological violence episodes and $39 \%$ of physical violence episodes were not reported.

The analysis of the reasons for not reporting revealed that the respondents believe that reporting the incident is useless ( $41 \%$ for psychological violence, $28 \%$ for physical violence) or unimportant ( $20 \%$ for psychological violence, $28 \%$ for physical violence). A personal sense of guilt or fear of the repercussions of reporting incidents was also noted. In this study, many employees (41\%) felt that programs for the prevention and management of violence were unsatisfactory.

The results of this study revealed that intervention programs on violence should recognize 2 distinct needs: (a) programs to prevent violence and encourage reporting and (b) programs to provide support for victims of violence. The emphasis of these programs may, however, differ.

Violence against HCWs is a serious problem, and a recent review has suggested that it accounts for $75 \%$ of all workplace violence. ${ }^{4,5}$

While some consider psychological violence as a harbinger of physical violence, ${ }^{13,14}$ its frequency and impact suggest that it should in itself be considered as an important adverse outcome of health-care work. ${ }^{15-19}$

Different rates of violence experienced among HCWs have been reported in studies from several countries. ${ }^{8,15,18-31}$ Although this may reflect actual differences in rates of violence, the diversity may also be due to the different methods used to collect or summarize the information (eg, prevalence, incidence, attack rate, etc.).

The violence rates found in our study are generally comparable to incidences from several countries but also differ from others. The rate of workplace violence was $62 \%$ in Lebanon ${ }^{15}$ and $67 \%$ in Riyadh, Saudi Arabia. ${ }^{8}$ In Turkey, $68.1 \%$ reported having experienced verbal violence, $13.8 \%$ reported having experienced physical violence, and $18.1 \%$ reported having experienced both. ${ }^{6}$ The US Minnesota Nurses' study estimated the annual incidence of verbal assaults and physical assaults to be $39 \%$ and 13\%, respectively. ${ }^{9}$ From 1993 through 2001, violence against physicians in the US occurred at a rate of 10.1 per 1000 workers. ${ }^{16} \mathrm{HCWs}$ ' risk of experiencing violence is greater than the risks in the general US worker population. The Bureau of Justice Statistics National Crime Victimization Survey estimated the annual average rate of simple assault in the workplace from 2002 to 2011 for government employees as 18.9 per 1000 and for private sector employees as 4.6 per 1000 . These approximately correspond to the annual percentages of $2 \%$ and $0.5 \%$, respectively. ${ }^{17}$

Statistics concerning verbal abuse (psychological violence) and pushing (physical violence) in this study are consistent with those of previous studies. ${ }^{18-22}$ Young HCWs experienced the biggest number of episodes of both physical and psychological violence in this study, which is consistent with studies in southern Taiwan, Lebanon, southern Ethiopia, and Riyadh. ${ }^{8,15,18,19}$

Other researchers have reported different and contradictory results by gender. For example, a study in southern Ethiopia and another study in Australia found that the female gender was positively associated with the experience of workplace violence, ${ }^{19,21}$ but studies in Saudi Arabia, Palestine, and Barbados found that males were more likely to be victims of violence. ${ }^{8,22,23}$

On the other hand, studies have reported that nurses experience violence at a higher rate. ${ }^{9,11,14,24-27}$

The findings in this study - the high rate of violence in inpatient departments and the profile of the perpetratorsare consistent with those of previous studies. It was furthermore reported in these studies that the hospital 
staff and management also contributed to violence. . $^{8,25,26,28,29}$

The underreporting of violence in this study is consistent with previous studies. ${ }^{10,23,30}$

Potential approaches to encourage reporting include adopting a zero-tolerance reporting policy requiring immediate reporting of an incident to a responsible person, ${ }^{4}$ supporting and encouraging employees to $\log$ and report all incidents to their supervisors, and possibly reporting incidents to the local police. In addition, other approaches may include informing victims of their legal right to prosecute perpetrators, sharing information about incidents, and having a sensitive discussion about the circumstances of the incident. ${ }^{30-32}$ Many of these methods have been reported by other programs, as in the Occupational Safety and Health Administration fact sheet "Workplace Violence". 2 We believe the Dammam Medical Complex may recognize the significance of this problem and allocate resources to implement programs for both surveillance and assisting workers subjected to violence.

Results of systematic studies such as the present study can guide targeted approaches. For example, prevention strategies should be targeted at all age groups, whereas support strategies should be more focused on younger workers since they are more vulnerable. This recommendation is also supported by analysis related to years of work experience, where the physicians and nurses with fewer years of work experience (under 5 years) were more likely to experience either physical or psychological violence. This may be because younger physicians and nurses have limited experience with dealing with violence or because new workers are often assigned to crowded areas, such as emergency rooms. Future research should also evaluate whether programs for nurses and physicians should differ - for example, the suggested prevention programs of both the National Institute for Occupational Safety and Health and the WHO do not target workers by discipline. ${ }^{31-33}$

Suggested methods to prevent violence include safeguards to prevent violence before it occurs, installing security cameras, changing the environmental design (especially in high-risk areas), training workers in deescalation, self-defense, and conflict resolution, adopting better administration policies to increase the number of staff, reducing waiting time, and labeling the files of offending patients to warn staff. Making all staff aware of the procedure for handling reported incidents was found to encourage the reporting of violent incidents in hospital settings. ${ }^{34}$ Advising patients and families about zero tolerance and refusal to treat violent patients could also be considered. Suggested administrative controls include preventing personnel from working alone by designing a staffing pattern, using card-controlled access to check non-staff movement inside the hospital, and providing a system for alerting security personnel. ${ }^{33}$

This paper, which includes data on the documentation of incident reporting and subsequent handling of the incidents, could add to the international literature on violence in healthcare facilities. The results suggest that a violence prevention program needs to be developed, evaluated, and implemented for hospitals to achieve quality health-care services.

\section{Limitations of This Study}

This study has a few limitations. First, results may be subjected to recall bias since the results were based on self-reported data over a 12-month period. Second, the study employed a cross-sectional design to estimate the prevalence of exposure and risk factors and, therefore, does not demonstrate a temporal relationship between risk factors and workplace violence. Third, this study is limited to 1 specific hospital and might not be generalizable to the entire region or country. Fourth, we did not adjudicate questionnaire data with other documents such as incident reports. Fifth, a small number of participants reported physical violence, and hence the lack of statistical difference in the statistical analysis may be explained by inadequate sample size.

\section{Conclusions}

Violence against HCWs in the hospital under study was found to be very common. The results suggest that a violence prevention program needs to be developed, evaluated, and implemented for the hospital to achieve quality health-care services. While further research and surveillance approaches are necessary, this study makes a start toward characterizing workplace violence against physicians and nurses in a major medical complex in Saudi Arabia. We recommend that other hospitals undertake the same exercise. It may also be worth understanding if an influx of foreign patients in hospitals servicing pilgrims during the Hajj and for the Umrah, as well as those visiting Medina, may produce different levels of violence in the hospitals around Makkah and Medina ( 2 holy places in Saudi Arabia where millions of Muslims from abroad travel every year). 


\section{Author Contributions}

All authors made a significant contribution to the work reported, whether that is in the conception, study design, execution, acquisition of data, analysis and interpretation, or in all these areas; took part in drafting, revising or critically reviewing the article; gave final approval of the version to be published; have agreed on the journal to which the article has been submitted; and agree to be accountable for all aspects of the work.

\section{Disclosure}

This work was not supported or funded by any drug company.

This article was not presented in conference proceedings.

The authors report no conflicts of interest for this work.

\section{References}

1. World Health Organisation. Framework guidelines for addressing workplace violence in the health sector. Available from: http://www. who.int/violence_injury_prevention/injury/work9/en/. Accessed May $28,2020$.

2. OSHA. What is workplace violence? https://www.osha.gov/OshDoc/ data_General_Facts/factsheet-workplace-violence.pdf. Accessed November 30, 2017.

3. Li YL, Li RQ, Qiu LD, Yuan Xiao SY. Prevalence of workplace physical violence against health-care professionals by patients and visitors: a systematic review and meta-analysis. Int J Environ Res Public Health. 2020;17(1):299. doi:10.3390/ijerph17010299

4. Phillips JP, Longo DL. Workplace violence against health-care workers in the United States. N Engl J Med. 2016;374(17):1661-1669. doi:10.1056/NEJMra1501998

5. OSHA; US Department of Labor. Guidelines for preventing workplace violence for healthcare and social service workers. Available from: https:// www.osha.gov/Publications/osha3148.pdf. Accessed May 28, 2020.

6. Ramacciati N, Ceccagnoli A, Addey B. Violence against nurses in the triage area: an Italian qualitative study. Int Emerg Nurs. 2015;23 (4):274-280. doi:10.1016/j.ienj.2015.02.004

7. Al-Omari H. Physical and verbal workplace violence against nurses in Jordan. Int Nurs Rev. 2015;62(1):111-118. doi:10.1111/inr.12170

8. Algwaiz WM, Alghanim SA. Violence exposure among health-care professionals in Saudi public hospitals. A preliminary investigation. Saudi Med J. 2012;33(1):76-82.

9. Fafliora E, Bampalis VG, Zarlas G, Sturaitis P, Lianas D, Mantzouranis G. Workplace violence against nurses in three different Greek healthcare settings. Work. 2015;53(3):551-560. doi:10.3233/ WOR-152225

10. Fallahi KM, Oskouie F, Ghazanfari N, et al. The frequency, contributing and preventive factors of harassment towards health professionals in Iran. Int J Community Based Nurs Midwifery. 2015;3 (3):156-164.

11. Alkorashy HA, Al Moalad FB. Workplace violence against nursing staff in a Saudi university hospital. Int Nurs Rev. 2016;63 (2):226-232. doi:10.1111/inr.12242

12. ILO/ICN/WHO/PSI. Workplace violence in the health sector, Survey Questionnaire. Available from: http://www.who.int/violence_injury_ prevention/violence/interpersonal/en/WVquestionnaire.pdf. Accessed May 28, 2020.
13. Pompeii LA, Schoenfisch AL, Lipscomb HJ, Dement JM, Smith CD, Upadhyaya M. Physical assault, physical threat, and verbal abuse perpetrated against hospital workers by patients or visitors in six U.S. hospitals. Am J Ind Med. 2015;58(11):1194-1204. doi:10.1002/ajim.22489

14. Shi L, Zhang D, Zhou C, et al. A cross-sectional study on the prevalence and associated risk factors for workplace violence against Chinese nurses. BMJ Open. 2017;7(6):e013105. doi:10.1136/bmjopen-2016-013105

15. Alameddine M, Mourad Y, Dimassi H. A national study on nurses' exposure to occupational violence in lebanon: prevalence, consequences and associated factors. PLoS One. 2015;10(9):e0137105. doi:10.1371/journal.pone.0137105

16. Kumar M, Verma M, Das T, Pardeshi G, Kishore J, Padmanandan A. A study of workplace violence experienced by doctors and associated risk factors in a tertiary care hospital of South Delhi, India.. J Clin Diagn Res. 2016;10(11):LC06-LC10. doi:10.7860/JCDR/2016/ 22306.8895

17. Bureau of Justice Statistics. Workplace Violence against Government Employees, 1994-2011; 2013. Available from: http://www.bjs.gov/ index.cfm?ty=pbdetail\&iid=4615. Accessed May 28, 2020.

18. Magnavita N, Heponiemi T. Violence towards health-care workers in a public health-care facility in Italy: a repeated cross-sectional study. BMC Health Serv Res. 2012;12(1):108. doi:10.1186/1472-6963-12-108

19. Fute M, Mengesha ZB, Wakgari N, Tessema GA. High prevalence of workplace violence among nurses working at public health facilities in Southern Ethiopia. BMC Nurs. 2015;14(1):9. doi:10.1186/s12912015-0062-1

20. Aksakal FN, Karasahin EF, Dikmen AU, Avci E, Ozkan S. Workplace physical violence, verbal violence, and mobbing experienced by nurses at a university hospital. Turk J Med Sci. 2015;45:1360-1368. doi:10.3906/sag-1405-65

21. Cashmore AW, Indig D, Hampton SE, Hegney DG, Jalaludin BB. Factors influencing workplace violence risk among correctional health workers: insights from an Australian survey. Aust J Prim Health. 2016;22(5):461-465. doi:10.1071/PY15071

22. Kitaneh M, Hamdan M. Workplace violence against physicians and nurses in Palestinian public hospitals: a cross-sectional study. BMC Health Serv Res. 2012;12(1):469. doi:10.1186/1472-6963-12-469

23. Abed M, Morris E, Sobers-Grannum N. Workplace violence against medical staff in healthcare facilities in Barbados. Occup Med (Lond). 2016;66(7):580-583. doi:10.1093/occmed/kqw073

24. Nayyer-ul I, Yousuful-Islam M, Farooq MS, Mazharuddin SM, Hussain SA. Workplace violence experienced by doctors working in government hospitals of Karachi. J Coll Physicians Surg Pak. 2014;24(9):698-699.

25. da Silva AT, Peres MF, Lopes Cde S, Schraiber LB, Susser E, Menezes PR. Violence at work and depressive symptoms in primary health-care teams: a cross-sectional study in Brazil. Soc Psychiatry Psychiatr Epidemiol. 2015;50(9):1347-1355. doi:10.1007/s00127015-1039-9

26. AbuAlRub RF, Al Khawaldeh AT. Workplace physical violence among hospital nurses and physicians in underserved areas in Jordan. J Clin Nurs. 2014;23(13-14):1937-1947. doi:10.1111/ jocn. 12473

27. Tiruneh BT, Bifftu BB, Tumebo AA, Kelkay MM, Anlay DZ, Dachew BA. Prevalence of workplace violence in Northwest Ethiopia: a multivariate analysis. BMC Nurs. 2016;15(1):1-6. doi:10.1186/s12912-016-0162-6

28. Cheung T, Lee PH, Yip PSF. Workplace Violence toward physicians and nurses: prevalence and correlates in Macau. Int J Environ Res Public Health. 2017;14(8):pii: E879. doi:10.3390/ijerph14080879

29. Lu L, Dong M, Wang SB, et al. Prevalence of workplace violence against health-care professionals in China: a comprehensive meta-analysis of observational surveys. Trauma Violence Abuse. 2020;21(3):498-509. 
30. Jiao M, Ning N, Li Y, et al. Workplace violence against nurses in Chinese hospitals: a cross-sectional survey. BMJ Open. 2015;5(3) e006719. doi:10.1136/bmjopen-2014-006719

31. Wei CY, Chiou ST, Chien LY, Huang N. Workplace violence against nurses - Prevalence and association with hospital organizational characteristics and health-promotion efforts: cross-sectional study. Int J Nurs Stud. 2016;56:63-70. doi:10.1016/j.ijnurstu.2015.12.012

32. Arbury S, Zankowski D, Lipscomb J, Hodgson M. Workplace Violence Training Programs for Health Care workers: an analysis of program elements. Workplace Health Saf. 2017;65(6):266-272. doi:10.1177/2165079916671534
33. Halpern LW. OSHA considers national standard to prevent health-care workplace violence. Am J Nurs. 2017;117(4):15. doi:10.1097/01.NAJ.0000515216.84968.7c

34. Hogarth KM, Beattie J, Morphet J. Nurses' attitudes towards the reporting of violence in the emergency department. Australas Emerg Nurs J. 2016;19(2):75-81. doi:10.1016/j.aenj.2015.03.006

\section{Publish your work in this journal}

Risk Management and Healthcare Policy is an international, peerreviewed, open access journal focusing on all aspects of public health, policy, and preventative measures to promote good health and improve morbidity and mortality in the population. The journal welcomes submitted papers covering original research, basic science, clinical \& epidemiological studies, reviews and evaluations, guidelines, expert opinion and commentary, case reports and extended reports. The manuscript management system is completely online and includes a very quick and fair peer-review system, which is all easy to use. Visit http://www.dovepress.com/testimonials.php to read real quotes from published authors.

Submit your manuscript here: https://www.dovepress.com/risk-management-and-healthcare-policy-journal 